\title{
Nanoscale
}

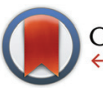

CrossMark \& click for updates

Cite this: Nanoscale, 2015, 7, 6093

Received 21st December 2014, Accepted 23rd February 2015

DOI: 10.1039/c4nr07531e

www.rsc.org/nanoscale

\section{Evolution, kinetics, energetics, and environmental factors of graphene degradation on silicon dioxide}

\author{
Susmit Singha Roy, ${ }^{a}$ Nathaniel S. Safron, ${ }^{a}$ Meng-Yin $\mathrm{Wu}^{\mathrm{b}}$ and Michael S. Arnold*a
}

Recent studies have qualitatively shown that the oxidative stability of monolayer graphene integrated on oxides is relatively poor. Here, the evolution, kinetics, and energetics of this degradation are quantified. Specifically, the deterioration of graphene on $\mathrm{SiO}_{2}$ is studied in grain interiors and at grain boundaries in ambient air, dry air and nitrogen between 473 and $673 \mathrm{~K}$, using spatially and temporally resolved in situ Raman spectroscopy in addition to electron microscopy and charge transport measurements. The grain interiors of chemical vapor deposition (CVD) grown graphene monolayers oxidize with an activation energy of $0.63 \pm 0.05 \mathrm{eV}$ in ambient air (15000 ppm $\mathrm{H}_{2} \mathrm{O}$ ). This energy increases to $1.85 \pm 0.17 \mathrm{eV}$ in dry air, whereas degradation is immeasurable in nitrogen and for multilayers even in ambient air. Gasification at grain boundaries in a CVD monolayer proceeds at a rate of $(1.08 \pm 0.02) \times 10^{-1} \mathrm{~nm} \mathrm{~s}^{-1}$ at $673 \mathrm{~K}$ with an activation energy $E_{\mathrm{A}}=1.14 \pm 0.10 \mathrm{eV}$ in ambient air. The more facile degradation of the monolayer grain interiors in ambient air indicates the role of the substrate in decreasing the stability against oxidation. The electrical transport mobility decays with an activation rate similar to that of grain interiors. These results can be used to quantitatively predict graphene oxidation and gasification on $\mathrm{SiO}_{2}$ in different environments and temperatures.

\section{Introduction}

The integration and support of graphene on a substrate is a necessary aspect for exploiting this two-dimensional material with exceptional properties in next generation electronic and optoelectronic applications. A major portion of the device architectures that have already been proposed and demonstrated specifically use glass, $\mathrm{SiO}_{2}$, or other oxides as supporting substrates. ${ }^{1-8}$ One potential challenge in using oxides as substrates, however, is that the chemical stability of single layers of graphene integrated on them is relatively poor. ${ }^{9-13}$ For example, it has been qualitatively observed that single layers of graphene degrade faster at lower temperatures on $\mathrm{SiO}_{2} / \mathrm{Si}$ substrates than graphene on non-polar substrates or graphene that is suspended. ${ }^{9}$ Sharma et al. have previously shown that on $\mathrm{SiO}_{2} / \mathrm{Si}$, single layer graphene is chemically more reactive to aryl diazonium reactants than bi-layer graphene. ${ }^{10}$ In a recent study, Yamamoto et al. qualitatively observed that charge inhomogeneity on the supporting substrate's surface enhances the oxidation of a mechanically exfoliated graphene monolayer and reported that single layers of

\footnotetext{
${ }^{a}$ Department of Materials Science and Engineering, University of WisconsinMadison, Madison, Wisconsin, USA. E-mail: msarnold@wisc.edu; Fax: +(608) 262-8353; Tel: +(608) 262-3863

${ }^{b}$ Department of Electrical and Computer Engineering, University of WisconsinMadison, Madison, Wisconsin, USA
}

graphene on $\mathrm{SiO}_{2}$ also oxidize faster than multiple layers of graphene. ${ }^{11}$ Furthermore, they observed an increased sensitivity of graphene monolayers to oxidation on a rougher $\mathrm{SiO}_{2}$ nanoparticle film compared to that on a smoother thermally grown $\mathrm{SiO}_{2} / \mathrm{Si}$ film, suggesting that an increased substrate surface roughness can also increase the rate of oxidation. While these qualitative studies serve as an important proof-ofprinciple, a better quantitative understanding of this relatively poor oxidative stability of monolayer graphene on $\mathrm{SiO}_{2}$ and similar oxide and polar substrates is needed to guide the engineering of future graphene based devices.

Here, we quantify the degradation (i.e. oxidation and gasification) of single layers of graphene on $\mathrm{SiO}_{2} / \mathrm{Si}$ substrates in order to learn more about this instability. $\mathrm{SiO}_{2} / \mathrm{Si}$ substrates are used as representative oxide substrates because they have been used extensively in the past in graphene and graphenebased field-effect transistors (FETs) and other electronic/optoelectronic devices. ${ }^{1-4}$ As shown in Fig. 1, multiple mechanisms contribute to the degradation. In order to differentiate among them, we study the degradation using several techniques. We (i) quantify the rates and kinetics of degradation, (ii) spatially map where the degradation occurred, (iii) determine environmental factors favoring degradation, and (iv) quantify effective activation energies.

In section 2.1, we employ temporally-resolved and spatiallyaveraged in situ Raman spectroscopy to compare the oxidation kinetics of single layers of graphene produced by two different 


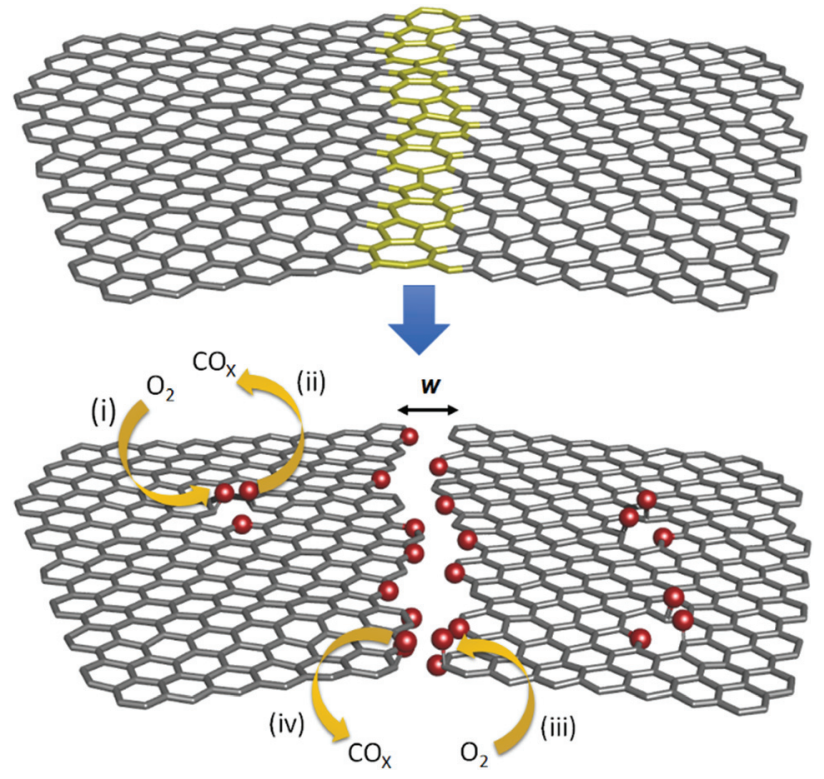

Fig. 1 Schematic of degradation processes. Top: as-manufactured graphene with grain boundaries highlighted in yellow. Bottom: graphene following degradation. Red represents oxygen atoms. Two modes of degradation are observed in this paper. One occurs in the grain interiors via oxidation (i) and gasification (ii). The second occurs at the grain boundaries and edges via oxidation (iii) and gasification (iv). Several different forms of oxygen functionalization are possible, with either $\mathrm{CO}$ or $\mathrm{CO}_{2}$ as gasification byproducts.

methods: chemical vapor deposition (CVD) and mechanical exfoliation. This oxidation was studied under the influence of different atmospheric conditions between 473 and $673 \mathrm{~K}$. It has been previously shown that (a) $\mathrm{O}_{2}$ plays an important role in the deterioration of $\mathrm{sp}^{2}$-bonded carbon materials and (b) $\mathrm{H}_{2} \mathrm{O}$ vapor accelerates the degradation process, ${ }^{14-22}$ hence we investigate the role of each of these species. Specifically, we vary the in situ atmospheric environment from (i) humid air to (ii) desiccated-dry air to (iii) nitrogen $\left(\mathrm{N}_{2}\right)$. In section 2.2 , in order to map where the oxidation and gasification take place, we use ex situ spatially-resolved imaging Raman spectroscopy (IRS). With the help of these techniques we show that the activation energy measured in section 2.1 corresponds to intragrain oxidation (i.e. the process depicted in Fig. 1i). In section 2.3 , we quantify the temperature dependence of the etch rate at grain boundaries (i.e. the process depicted in Fig. 1iii and iv) using time resolved scanning electron microscopy to determine the activation energy for gasification at receding grain edges.

Finally (section 2.4), to relate the deterioration to the electronic properties of single layers of graphene, we quantify the charge transport mobility and carrier concentration using in situ, temperature-dependent, field-effect transport measurements. Overall, this study will help in (i) understanding how environmental factors affect the integrity and properties of graphene, (ii) discerning the effect of the substrate on inducing defects in graphene, (iii) learning the limitations of graphene for applications which operate either at elevated temperatures or under ambient conditions such as gas-sensors, electrodes, or diffusion barriers, and (iv) overcoming these limitations.

\section{Results}

\subsection{Temporally-resolved and spatially-averaged in situ Raman spectroscopy}

Here, we use in situ Raman spectroscopy to quantify the accumulation of defects in graphene as it oxidizes with time (Fig. 1i), as a function of temperature between 473 and $673 \mathrm{~K}$, in humid air, desiccated dry air, and nitrogen. We quantify the defect density by measuring the ratio of the integrated Raman scattering intensity of the D-band $\left(\sim 1345 \mathrm{~cm}^{-1}\right.$ at $532 \mathrm{~nm}$ excitation) mode of graphene to the integrated Raman scattering intensity of the G-band mode $\left(\sim 1590 \mathrm{~cm}^{-1}\right.$ at $532 \mathrm{~nm}$ excitation), $I_{\mathrm{D}} / I_{\mathrm{G}}$. At a low defect density with an inter-defect separation, $L_{\mathrm{d}}$, that is $\gg 4 \mathrm{~nm}, I_{\mathrm{D}} / I_{\mathrm{G}}$ is linearly proportional to the defect density and thus can be used to compare defect densities as a function of time and conditions and between different samples. In contrast at high defect density, as $L_{\mathrm{d}}$ decreases and becomes comparable to $4 \mathrm{~nm}, I_{\mathrm{D}} / I_{\mathrm{G}}$ increases and then saturates at a maximum of 3 (for a Raman excitation wavelength of $514.5 \mathrm{~nm}){ }^{23,24}$ To ensure that we are confined to or near the linear regime, our time-resolved degradation experiments are terminated before an $I_{\mathrm{D}} / I_{\mathrm{G}}$ of 2 is reached. The spatial resolution of the technique is determined by the laser spot-size, which is $\sim 700 \mathrm{~nm}$. Substrate-induced topological features and charge inhomogeneity are expected to vary on a much finer lateral length scale of $\sim 10 \mathrm{~nm} \cdot{ }^{9,11,25}$ It is also important to point out that $I_{\mathrm{D}} / I_{\mathrm{G}}$ does not depend on the nature or the geometry of the defect (within the Raman spectrometer resolution) but only depends on the overall density, as previously shown by Eckmann et al. ${ }^{26}$ thus giving us an ideal way to quantify the density without having to separately account for contributions due to each type of defect. An in situ Raman heated-stage enclosure (Linkam THMS 600) is used to control the temperature of the sample and the atmosphere around it. To regulate the atmosphere, two different in situ experimental setups are used: (i) an open-lid setup is used to characterize degradation in humid air in which the sample is exposed to ambient humid air while being heated and (ii) a closed-lid set-up is used to confine the sample's ambient to desiccated-dry air and nitrogen. The Raman spectra are spatially averaged over $100 \times 100 \mu^{2}$ area.

We first study the oxidation (Fig. 1i) of graphene grown by atmospheric pressure CVD. The graphene is grown on $\mathrm{Cu}$ in $\mathrm{CH}_{4}$ and transferred to $\mathrm{SiO}_{2} / \mathrm{Si}$ via a standard sacrificial polymer approach using a thin film of poly(methyl methacrylate) to support the graphene during the removal of the $\mathrm{Cu}$ growth substrate/catalyst in the ammonium persulfate (25\% Transene company, Inc. APS- $100+75 \%$ DI water) $\mathrm{Cu}$ etchant. ${ }^{8,27}$ After transfer to $\mathrm{SiO}_{2} / \mathrm{Si}$, the poly(methyl methacrylate) is removed in acetone followed by rinsing in isopropyl alcohol and subsequently air-drying. The graphene on $\mathrm{SiO}_{2} / \mathrm{Si}$ 


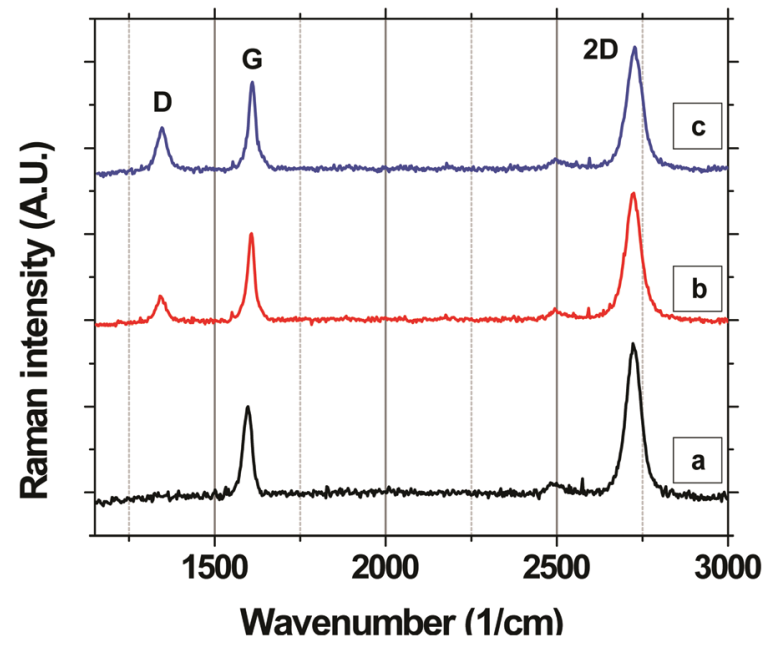

Fig. 2 Evolution of spatially-averaged Raman spectra of the monolayer graphene normalized to the intensity of the G-band annealed at $573 \mathrm{~K}$ in ambient air. The $I_{D} / I_{G}$ ratio increases from an initial value of 0.05 (a) to 0.26 (b) after being annealed for $5 \mathrm{k}$ seconds and then to 0.48 (c) after $10 \mathrm{k}$ seconds.

is then transferred to the Raman instrument and characterized.

Fig. 2a shows the Raman spectra of monolayer graphene on $\mathrm{SiO}_{2}$ spatially averaged over $100 \times 100 \mu \mathrm{m}^{2}$ area and normalized to the G-band intensity. The average $I_{\mathrm{D}} / I_{\mathrm{G}}$ measured for the area is 0.05 . When the sample is annealed in ambient air at $573 \mathrm{~K}$, the $I_{\mathrm{D}} / I_{\mathrm{G}}$ starts increasing with time. Fig. $2 \mathrm{~b}$ and $\mathrm{c}$ show representative Raman spectra of the sample after $5 \mathrm{k}$ seconds and 10k seconds of annealing, respectively. The average $I_{\mathrm{D}} / I_{\mathrm{G}}$ of the same area increases to 0.26 and 0.48 after $5 \mathrm{k}$ and $10 \mathrm{k}$ seconds, respectively.

The evolution of $I_{\mathrm{D}} / I_{\mathrm{G}}$ versus time is shown in Fig. 3a for CVD-grown graphene on $\mathrm{Si} / \mathrm{SiO}_{2}$ in humid air at a water vapor concentration of $15000 \mathrm{ppm}$ at 473, 573, and $673 \mathrm{~K}$. At each temperature, $I_{\mathrm{D}} / I_{\mathrm{G}}$ increases linearly with time, indicating that the defect density increases linearly with time. ${ }^{28}$ The rate of increase becomes faster with increasing temperature. It is important to keep in mind that the contribution to $I_{\mathrm{D}}$ arises primarily from the grain interiors (Fig. 1i) as opposed to that at grain boundaries (Fig. 1iii), as we show later in section 2.2. An initial lag in the onset of the linear increase in $I_{\mathrm{D}} / I_{\mathrm{G}}$ with time is observed (Fig. 3a, inset) and potentially can be attributed to desorption of residual surface adsorbents and contaminants that might have originated from the transfer process. As shown in Fig. $3 \mathrm{~b}$, the rate of change, $R$, in the linear regime has an Arrhenius dependence on the temperature, $T$, such that $R=(\partial / \partial t)\left(I_{\mathrm{D}} / I_{\mathrm{G}}\right)=R_{673} \exp \left[\left(-E_{\mathrm{A}} / k_{\mathrm{B}}\right)(1 / T-1 / 673)\right]$ where $R_{673}$ is a pre-exponential factor specifying the degradation rate at $T=$ $673 \mathrm{~K}$ and $E_{\mathrm{A}}$ is the activation energy. The fit $R_{673}=(3.7 \pm 0.7)$ $\times 10^{-4} \mathrm{~s}^{-1}$ and the fit $E_{\mathrm{A}}=0.63 \pm 0.05 \mathrm{eV}$, are over the range of 473 to $673 \mathrm{~K}$, where the error bars denote two standard deviations of certainty.
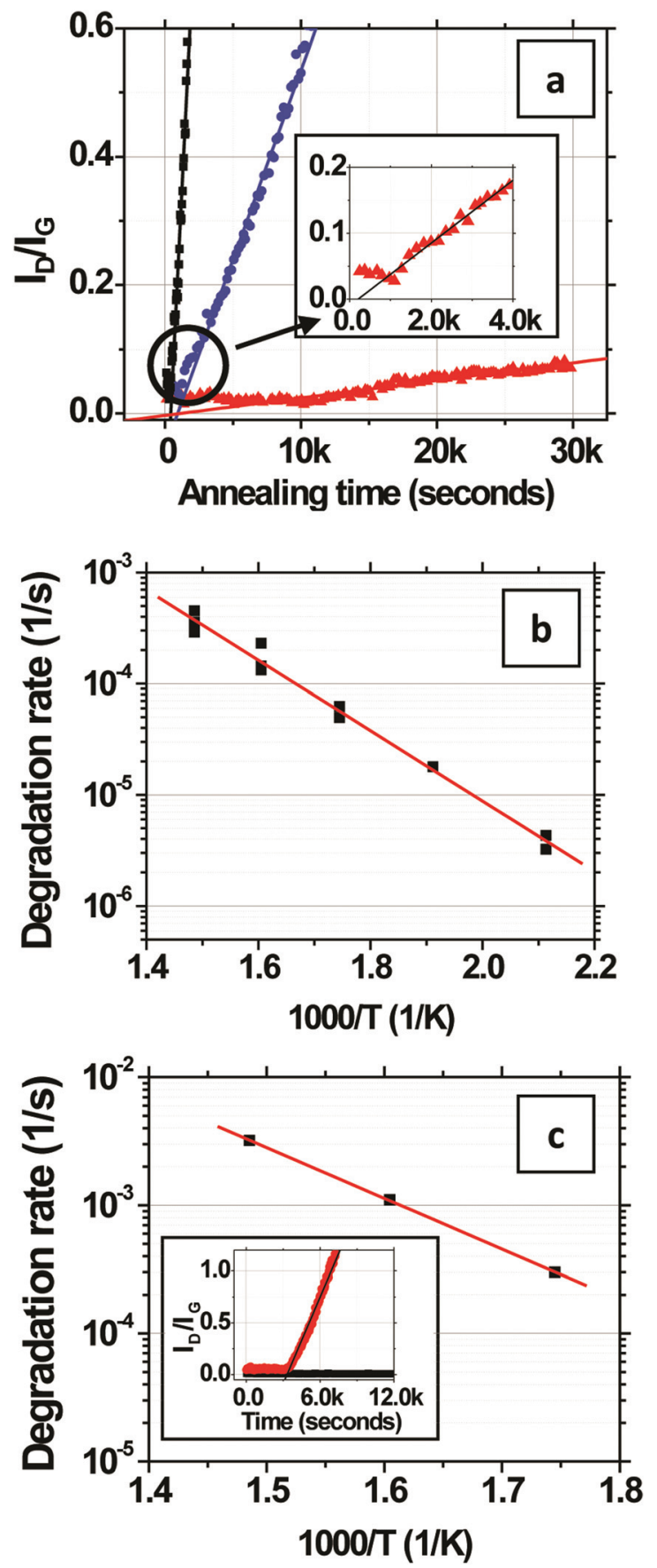

Fig. 3 Rate and kinetics of degradation of monolayer CVD-graphene on $\mathrm{SiO}_{2} / \mathrm{Si}$. (a) Red-triangles, blue-circles and black-squares represent the evolution of $I_{D} / I_{G}$ versus time in humid air (15000 ppm $\mathrm{H}_{2} \mathrm{O}$ ) at $473 \mathrm{~K}, 573 \mathrm{~K}$ and $673 \mathrm{~K}$, respectively. Inset: initial lag in the onset of the linear increase in $I_{\mathrm{D}} / I_{\mathrm{G}}$ with time. (b) Arrhenius dependence of the degradation rate $\left(\partial\left(I_{\mathrm{D}} / I_{\mathrm{G}}\right) / \partial t\right)$ with temperature $\left(R_{673}=(3.7 \pm 0.7) \times 10^{-4} \mathrm{~s}^{-1}, E_{\mathrm{A}}\right.$ $=0.63 \pm 0.05 \mathrm{eV})$ for CVD-graphene in humid air $\left(15000 \mathrm{ppm} \mathrm{H}_{2} \mathrm{O}\right)$. (c) Arrhenius dependence of the degradation rate $\left(\partial\left(I_{\mathrm{D}} / I_{\mathrm{G}}\right) / \partial t\right)$ with temperature $\left(R_{673}=(3.2 \pm 0.1) \times 10^{-3} \mathrm{~s}^{-1}, E_{\mathrm{A}}=0.79 \pm 0.01 \mathrm{eV}\right)$ for mechanically exfoliated graphene in humid air $\left(12000\right.$ ppm $\left.\mathrm{H}_{2} \mathrm{O}\right)$. Inset: comparison of the evolution of $I_{D} / I_{G}$ versus time for single (red) and multiple layers of mechanically exfoliated graphene (black) on $\mathrm{SiO}_{2} / \mathrm{Si}$ at $623 \mathrm{~K}$. 
The above experiment is also performed for mechanically exfoliated graphene transferred onto $\mathrm{SiO}_{2} / \mathrm{Si}$ to examine whether the initial "quality" of the graphene affects the kinetics or energetics of oxidation (Fig. 1i). Unlike the mechanically exfoliated graphene, the CVD graphene is stitched together via defective grain boundaries. In addition, the superior transport characteristics of exfoliated graphene ${ }^{29,30}$ suggest that the initial concentration of defects is lower in exfoliated graphene than in CVD graphene grown on $\mathrm{Cu}$ foils under the conditions used here. Moreover, mechanically exfoliated graphene is also flatter and single crystalline whereas the topology of CVD-grown graphene contains wrinkles and maintains the memory of the "rough" $\mathrm{Cu}$ foil catalyst substrates and is polycrystalline (average grain size here is $\sim 14 \mu \mathrm{m})$. The $I_{\mathrm{D}} / I_{\mathrm{G}}$ for mechanically exfoliated monolayer graphene is measured over a smaller area of $2 \times 2$ $\mu \mathrm{m}^{2}$ away from the edges of the flakes because of their limited size, in humid air at a water vapor concentration of $\sim 12000 \mathrm{ppm}$. The fit $R_{673}=(3.2 \pm 0.1) \times 10^{-3} \mathrm{~s}^{-1}$ and $E_{\mathrm{A}}=$ $0.79 \pm 0.01 \mathrm{eV}$ (Fig. 3c). While the small $20 \%$ difference in water vapor concentration between the experiments on CVD-graphene and mechanically exfoliated graphene precludes precise quantitative comparison, the relatively low $E_{\mathrm{A}}$ for both cases (compared with the much higher $E_{\mathrm{A}}$ measured in dry air below), indicates that the "quality" of the graphene and intrinsic defects do not substantially lower the effective $E_{\mathrm{A}}$ in humid air on $\mathrm{SiO}_{2} / \mathrm{Si}$ substrates. Rather, these data indicate the importance of extrinsic factors, for example graphene-substrate interactions, in driving the degradation.

In contrast to single layer graphene, mechanically exfoliated few $(1<n<4)$ layer graphene transferred to $\mathrm{SiO}_{2} / \mathrm{Si}$ is much more stable in humid air. The inset in Fig. 3c compares the evolution of $I_{\mathrm{D}} / I_{\mathrm{G}}$ versus time for single and multiple layers of graphene on $\mathrm{SiO}_{2} / \mathrm{Si}$ at $623 \mathrm{~K}$. Whereas $I_{\mathrm{D}} / I_{\mathrm{G}}$ for the single layer increases rapidly with time, $I_{\mathrm{D}} / I_{\mathrm{G}}$ for multiple layers does not measurably increase even after 3 hours. In both cases, the top layer of graphene is hot and exposed to the humid air. However, in the few layer sample, the top layer that is exposed to the humid air is isolated from the $\mathrm{SiO}_{2}$ substrate by the underlying layers, which themselves are not directly exposed to the ambient environment. Thus, graphene isolated from the $\mathrm{SiO}_{2}$ substrate oxidizes and gasifies very slowly even in humid air. These results suggest that substrate interactions play important roles in the degradation of single layers of graphene. While we cannot preclude the possibility that bi- or multi-layer graphene might be less reactive than single layer graphene, even in the absence of substrate-effects, it is well known that the different layers are coupled via a weak van der Waals interaction with only minor electronic perturbation. Taking this argument into account, the most likely explanation for the decreased reactivity of the topmost layer of the multilayer graphene is the isolation from the substrate. This explanation is further supported by the qualitative study of the chemical reactivity of graphene on various substrates by Yamamoto et al. ${ }^{11}$
It has been theoretically shown by Patra $e t a l$. that water can act as a catalytic element that initiates rapid conformational changes in single layers of graphene. ${ }^{21}$ Also, experimental studies indicate that water has the ability to intercalate at the graphene- $\mathrm{SiO}_{2}$ interface and deform the surface of the atomic membrane. ${ }^{19,22}$ These effects distort the graphene on the atomic scale creating deformation or curvature causing straininduced pyramidalization, which is known to increase the chemical reactivity. ${ }^{31}$ Therefore cumulatively, it can be hypothesized that the critical role of water on oxides may be to strain and deform single layers of graphene thereby decreasing the activation energy for oxidation (Fig. 1i).

To probe the effect of water vapor further, we next study the effect of reducing its concentration on the degradation rate and activation energy. In this case, we use the closed-lid setup and dry the wet ambient air using desiccants. The use of desiccants has the advantage of ensuring that the composition of the ambient air remains constant except for water vapor, which is reduced by the desiccants (as opposed to creating mixtures of dry $\mathrm{N}_{2}$ and $\mathrm{O}_{2}$ that are missing the other relevant components of an ambient atmosphere like $\mathrm{CO}$ and $\mathrm{CO}_{2}$ ). In the closed-lid setup, the humid ambient air is drawn through 3 cascaded drying tubes of desiccants $(1 \times$ silica gel, Fisher Chemical product \# S161-500 and $2 \times$ drierite, W.A. Hammond Drierite Indicating Drying Tube $8 " \mathrm{~L} \times 3 / 4^{\prime \prime}$ O.D.) and then through the sample chamber by pulling vacuum on the outlet port of the sample chamber. This approach reduces the water vapor concentration below the sensitivity of our hygrometer to $<2000 \mathrm{ppm}$. We also conduct a control experiment in the closed-lid setup using humid air without desiccants to test whether the flow of the gas over the substrate used in this closed-lid setup leads to differences in degradation compared to the open-lid setup used previously in which there was no forced flow. The humid air (water vapor concentration $\sim 15000 \mathrm{ppm})$ in the closed-lid setup yields a $R_{673}=(7.8 \pm 1.0)$ $\times 10^{-4} \mathrm{~s}^{-1}$ and an $E_{\mathrm{A}}=0.71 \pm 0.06 \mathrm{eV}$ (Fig. 4a), which is similar to the $E_{\mathrm{A}}$ of $0.63 \pm 0.05$ determined previously in the open-lid setup.

The degradation rate is substantially slower in dry air. At $623 \mathrm{~K}$, it is 100 times slower. The activation energy increases to $E_{\mathrm{A}}=1.85 \pm 0.17 \mathrm{eV}$ (Fig. 4a) with $R_{673}=(3.6 \pm 0.4) \times 10^{-5} \mathrm{~s}^{-1}$, which is $\sim 3$ times $E_{\mathrm{A}}$ in humid air. Both the above observations with the dry air indicate that water vapor present in the air plays a vital role in the degradation process on $\mathrm{SiO}_{2}$ which is consistent with the theoretical studies and qualitative observations made regarding conformational changes in the graphene on $\mathrm{SiO}_{2}$ in humid but not dry air by other groups. ${ }^{19-22} \mathrm{~A}$ previous study has shown that water vapor can independently abstract $\mathrm{C}$ atoms from the basal plane of graphite thereby creating new defects on the surface between 673 and $1573 \mathrm{~K}^{32}$ however, this effect seems to be secondary to substrate effects as evidenced by immeasurably slow degradation of the few layered graphene samples on $\mathrm{SiO}_{2}$ in humid air (inset, Fig. 3c).

To further investigate the thermal stability of single layers of graphene on $\mathrm{SiO}_{2}$, we measure the evolution of $I_{\mathrm{D}} / I_{\mathrm{G}}$ under a nitrogen atmosphere $\left(99.999 \% \mathrm{~N}_{2},<1 \mathrm{ppm} \mathrm{O}_{2},<1 \mathrm{ppm}\right.$ water 

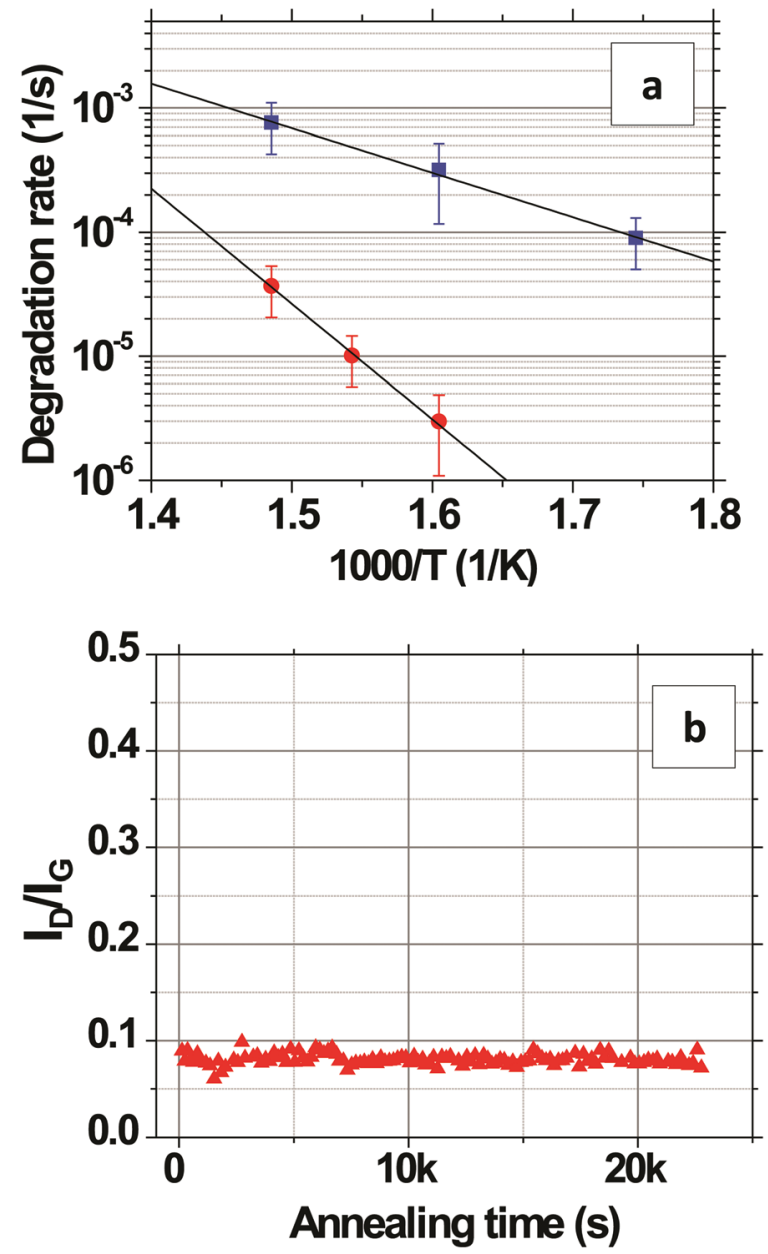

Fig. 4 (a) Arrhenius dependence of the degradation rate $\left(\left(\partial\left(I_{\mathrm{D}} / I_{\mathrm{G}}\right) / \partial t\right)\right.$ with temperature of monolayer CVD-graphene on $\mathrm{SiO}_{2} / \mathrm{Si}$ in humid air (blue-squares) and in desiccated-dry air (red-circles). $E_{\mathrm{A}}=0.71+0.06$ $\mathrm{eV}$ and $E_{\mathrm{A}}=1.85 \pm 0.17 \mathrm{eV}$ for CVD-graphene in humid air and desiccated-dry air, respectively. (b) Represents the evolution of $I_{\mathrm{D}} / I_{\mathrm{G}}$ versus time in nitrogen (99.999\%) for monolayer CVD-graphene on $\mathrm{SiO}_{2} / \mathrm{Si}$ at $623 \mathrm{~K}$.

vapor). As shown in Fig. 4b, no measurable degradation is observed at $623 \mathrm{~K}$ even after 7 hours of annealing, indicating that the quality of the graphene is unaffected even at elevated temperatures under inert conditions similar to what has been previously reported by several groups. ${ }^{33-38}$

\subsection{Ex situ spatially-resolved imaging Raman} spectroscopy (IRS)

Now that the rate and the activation energy for the oxidation of single layers of graphene on $\mathrm{SiO}_{2}$ are known, we next investigate and visualize the degradation using imaging Raman spectroscopy (IRS) and electron microscopy. To compare the contribution to $I_{\mathrm{D}} / I_{\mathrm{G}}$ from grain boundaries versus grain interiors, we imaged its spatial distribution using IRS at different times at $623 \mathrm{~K}$ in humid air. Fig. 5a and b (insets) show optical images of the regions of graphene on $\mathrm{SiO}_{2} / \mathrm{Si}$
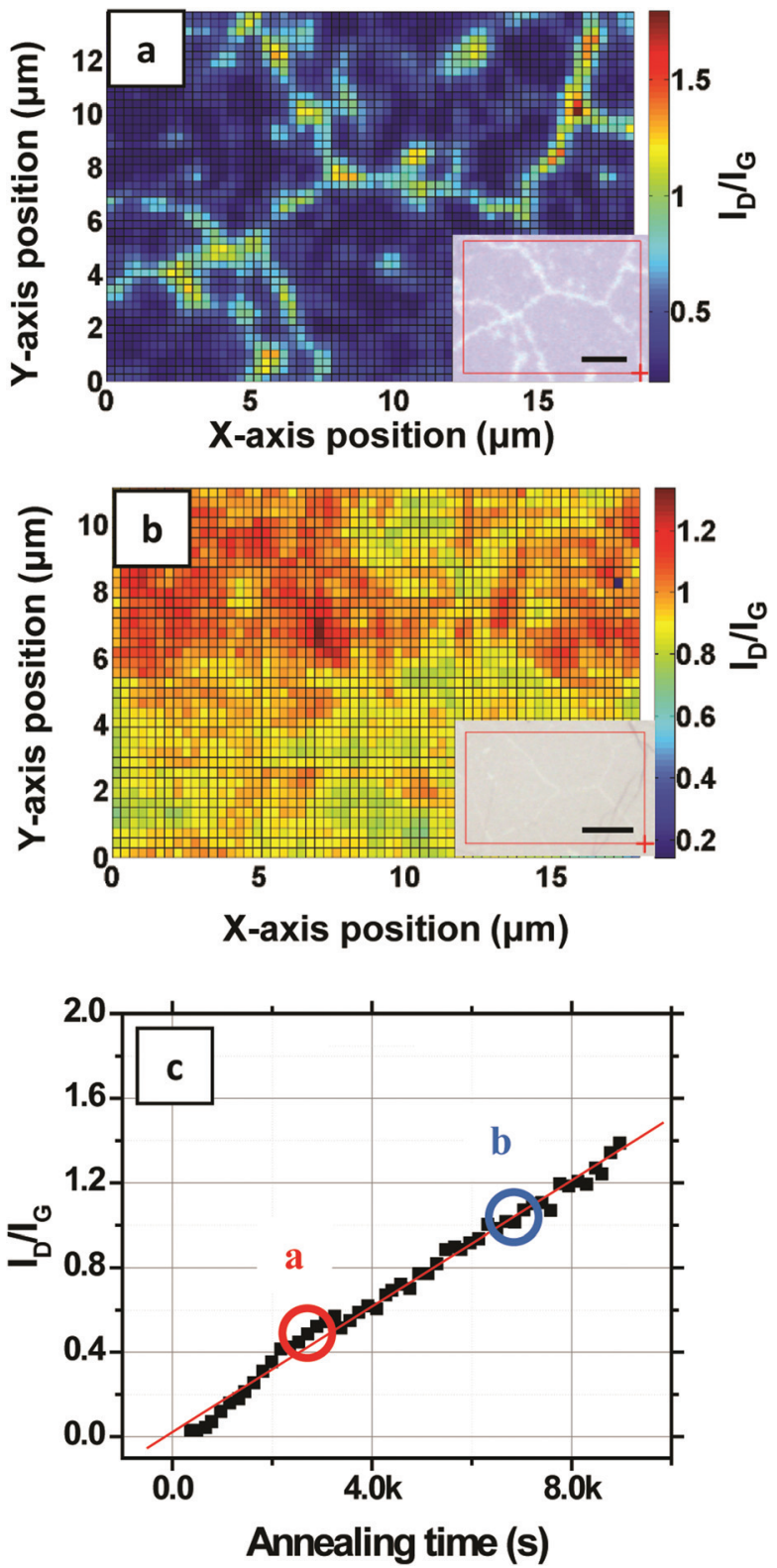

Fig. 5 Temporally resolved imaging Raman spectroscopy depicting the progression of the degradation process. (a) depicts the spatial distribution of $I_{D} / I_{G}$ over regions of visibly etched grain boundaries (as seen in the inset) after $45 \mathrm{~min}$ of annealing in humid air ( $15000 \mathrm{ppm} \mathrm{H}_{2} \mathrm{O}$ ) at $623 \mathrm{~K}$ and (b) depicts the same after 110 minutes of annealing (inset scalebars $=5 \mu \mathrm{m}$ ). (c) represents the evolution of $I_{\mathrm{D}} / I_{\mathrm{G}}$ versus time in humid air (15000 ppm $\mathrm{H}_{2} \mathrm{O}$ ) $623 \mathrm{~K}$, where dotted-circles ' $a$ ' and ' $b$ ' denote the instances corresponding to (a) and (b) above.

scanned after annealing for 45 and 110 minutes, respectively. Etching and gasification along grain boundaries and smaller circular features (etch pits) are evident from the optical images. The IRS maps of these same areas are shown in Fig. $5 \mathrm{a}$ and b. After 45 minutes (Fig. 5a), the $I_{\mathrm{D}} / I_{\mathrm{G}}$ is most intense at the grain boundaries. The graphene that has been etched and gasified at the grain boundaries (Fig. 1iii and iv) no longer contributes to this $I_{\mathrm{D}} / I_{\mathrm{G}}$ because this carbon has 
been removed as $\mathrm{CO}$ and $\mathrm{CO}_{2}$, but rather the carbon remaining at the edges of the graphene grains gives rise to the intense $I_{\mathrm{D}} / I_{\mathrm{G}}$ signal. More importantly, substantial oxidation (Fig. 1i) has also occurred within the grains. The average $I_{\mathrm{D}} / I_{\mathrm{G}}$ at the grain boundaries (determined by averaging $I_{\mathrm{D}} / I_{\mathrm{G}} \pm 0.4 \mu \mathrm{m}$ along each grain boundary) is 0.80 whereas the average $I_{\mathrm{D}} / I_{\mathrm{G}}$ in the remaining grain interiors is 0.23 . Even though $I_{\mathrm{D}} / I_{\mathrm{G}}$ at the grain edges is higher, the area occupied by the grain interiors is much larger; therefore the $I_{\mathrm{D}} / I_{\mathrm{G}}$ spatially averaged over the entire image $(=0.4)$ is actually dominated by the grain interiors. For example, spatially weighing, we find that $70 \%$ of the overall $I_{\mathrm{D}} / I_{\mathrm{G}}$ comes from the interiors whereas only $30 \%$ of the $I_{\mathrm{D}} / I_{\mathrm{G}}$ comes from the grain boundaries. Moreover, the $I_{\mathrm{D}} / I_{\mathrm{G}}$ at the grain edges should remain invariant with time because new oxidation at the grain edges is accompanied by new gasification, as discussed in section 2.3 below. Thus, the spatially averaged data and activation energies presented in section 2.1 are indicative of the oxidation (Fig. 1i) that occurs within the grains. After 110 minutes (Fig. $5 \mathrm{~b}$ ), the $I_{\mathrm{D}} / I_{\mathrm{G}}$ at the grain interiors and the grain edges becomes indistinguishable and the integrated average of the ratio becomes $\sim 1.0$. The above results again highlight that the deterioration proceeds via two different processes that occur with different kinetics: (a) the oxidation of the grain interiors (Fig. 1i) and (b) oxidation and gasification at grain boundaries and edges (Fig. 1iii and iv). Whereas the kinetics of the oxidation of the grain interiors are quantified via Raman spectroscopy above, the kinetics of the oxidation and gasification of grain edges are quantified in section 2.3 below.

\subsection{Temperature dependence of the grain boundary etch rate}

We next use time-resolved scanning electron microscopy (SEM) to quantify and image the gasification process at the grain edges. A single layer of CVD-grown graphene is transferred to $\mathrm{SiO}_{2} / \mathrm{Si}$ and split into several smaller pieces. The samples are maintained at a constant temperature $(673 \mathrm{~K})$ in humid air (water vapor $=15000 \mathrm{ppm}$ ) in the open-lid Raman chamber and removed at intervals of 15 minutes and then imaged by the SEM as shown in Fig. 6. The first visually obvious signatures of etching are at (i) grain-boundaries in the graphene (orange dashed lines), (ii) linear striations in the graphene (black dashed lines), which are spatially commensurate with rough, linear striations in the $\mathrm{Cu}$ foil growth substrate that arise from its manufacture, and (iii) random spots (yellow encircled feature) in the graphene grain interiors presumably from point/other surface defects that are present in the asgrown graphene. With time (Fig. 6) these etch pits and lines grow wider. Our observations are consistent with previous experimental and theoretical studies where it has been shown that graphitic materials selectively etch or oxidize at intrinsic and induced defects. ${ }^{13,39-41}$ The dark lines in Fig. 6 are wrinkles or folds in the graphene layer which originate from a mismatch between the thermal expansion coefficient of the atomic membrane and the $\mathrm{Cu}$ substrate. ${ }^{42}$ It can be noted that these folds etch relatively slowly and are more stable (Fig. 6a-d), presumably because they are elevated off the $\mathrm{SiO}_{2}$ substrate. ${ }^{43}$ It is important to note that the scale of these wrinkles and folds is much larger than the atomic-scale deformation induced by water-mediated interactions with the substrate. While the latter deformation occurs over a few lattice constants of graphene leading to an increased reactivity, the former deformation via wrinkling and folding occurs over a much longer length scale and elevates the graphene off the substrate thereby increasing its oxidative stability.

We capture electron micrographs as a function of time and temperature and calculate the average etch-width of the grain boundaries over a cumulative-length of $>200 \mu \mathrm{m}$ using an image analysis algorithm. From these data, we are able to calculate the etch rate at a grain boundary edge at a given temperature and also the temperature dependence of this rate and the activation energy. The histograms in Fig. 7a-c show the frequency distribution of the grain boundary widths after 240 , 105 , and 45 minutes of etching at 573, 623, and $673 \mathrm{~K}$, respectively. From the mode of these distributions fit to log-normal distributions, we find that the grain edges etch with a mode velocity of $3.6 \times 10^{-3}, 2.3 \times 10^{-2}$, and $1.1 \times 10^{-1} \mathrm{~nm} \mathrm{~s}^{-1}$ at 573 , 623, and $673 \mathrm{~K}$, respectively. The temperature dependence of the mode velocity can be represented by $v=v_{673} \exp \left[\left(-E_{\mathrm{A}} / k_{\mathrm{B}}\right)\right.$ $(1 / T-1 / 673)]$ with $v_{673}=(1.08 \pm 0.02) \times 10^{-1} \mathrm{~nm} \mathrm{~s}^{-1}$ and $E_{\mathrm{A}}=$ $1.14 \pm 0.10 \mathrm{eV}$. Several previous studies have investigated the

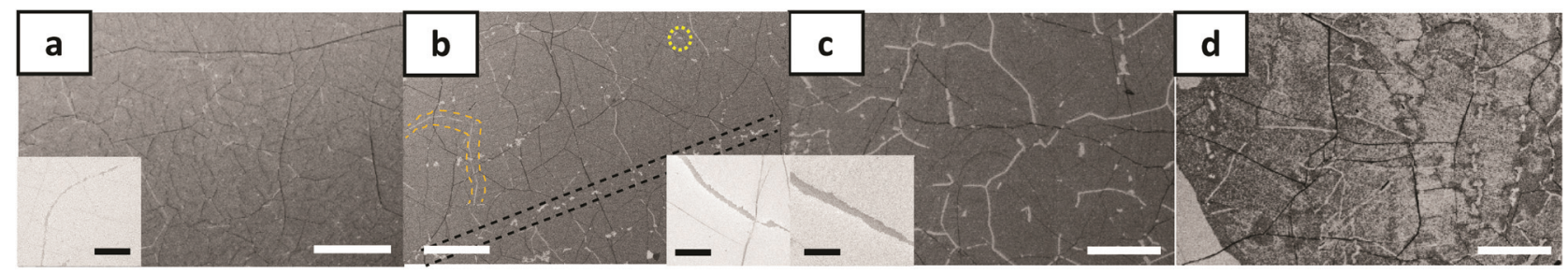

Fig. 6 Evolution of etching of monolayer CVD-graphene on $\mathrm{SiO}_{2} / \mathrm{Si}$ : (a), (b), (c) and (d) represent 15, 30, 45 and 60 minute etch periods in humid air $\left(15000 \mathrm{ppm} \mathrm{H} \mathrm{H}_{2} \mathrm{O}\right.$ ) at $673 \mathrm{~K}$ (white scalebars $=10 \mu \mathrm{m}$ and black scalebars $=1 \mu \mathrm{m}$ ). Contrast of the etched grain boundaries is reversed in the insets due to charging and deposition of carbon on the $\mathrm{SiO}_{2}$ substrate which is commonly observed during high magnification imaging in the scanning electron microscope. (b) also shows the first visually obvious signatures of etching at (i) grain boundaries in the graphene (orange dashed lines), (ii) linear striations in the graphene (black dashed lines), which are spatially commensurate with rough, linear striations in the Cu foil, and (iii) random spots (yellow encircled feature) in the graphene grain interiors presumably from point/other surface defects that are present in the as-grown graphene. 

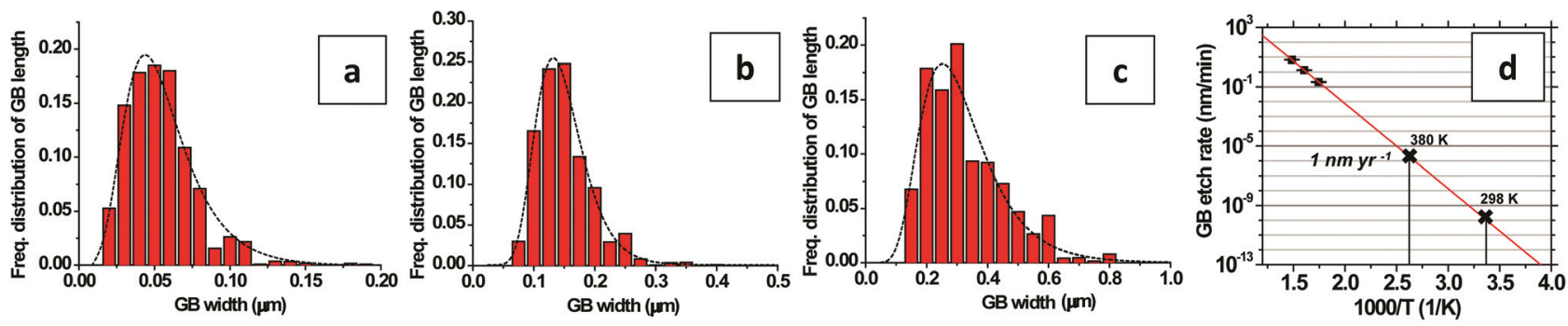

Fig. 7 Temperature dependence of the grain boundary etch rate: (a), (b), and (c) represent the frequency distribution of the grain boundary widths after 240, 105, and 45 minutes of etching at 573, 623, and $673 \mathrm{~K}$, respectively, fit to a log-normal curve. The fits from (a), (b) and (c) are used to determine the etch rates at the respective temperatures and (d) depicts the Arrhenius dependence of these rates on the temperature $\left(E_{\mathrm{A}}=1.14 \pm\right.$ $0.10 \mathrm{eV})$.

analogous gasification of graphite from crystal edges, reporting large variations in the measured $E_{\mathrm{A}}$ from 0.7 to $2.0 \mathrm{eV}^{14,32,44-46}$ However, differences in the experimental $\mathrm{O}_{2}$ and $\mathrm{H}_{2} \mathrm{O}$ concentrations and the temperature range between our study and these past studies of graphite make direct comparison difficult. Whereas the $E_{\mathrm{A}}$ of $0.63 \pm 0.05 \mathrm{eV}$ measured in section 2.1 quantifies the activation energy for the oxidation (Fig. 1i) of the grain interiors, the $E_{\mathrm{A}}$ of $1.14 \pm 0.10 \mathrm{eV}$ measured in this section quantifies the activation energy for the gasification of the grain edges (Fig. 1iv).

Sections 2.1-2.3, combined, allow us to paint a more detailed picture of the degradation of graphene monolayers, which occurs via a two-step process: oxidation followed by gasification as $\mathrm{CO}$ or $\mathrm{CO}_{2}$. Our data show that the barrier for the oxidation of pristine grain interiors (Fig. 1i) is lowered to $0.63 \pm 0.05 \mathrm{eV}$ in humid air on $\mathrm{SiO}_{2}$ substrates. Theory has also shown that the pre-existing point (e.g. vacancy) and graphene edges (Fig. 1iii) will oxidize in air in a barrierless process. ${ }^{14}$ Thus, pre-existing defects and the pristine grain interiors will oxidize, with either no barrier or a small $0.63 \mathrm{eV}$ barrier, respectively, relatively rapidly even at a modest temperature. It is thought that adsorbed oxygen molecules will dissociate to form oxygen based stationary functional groups like $-\mathrm{C}=\mathrm{O}$, $-\mathrm{C}-\mathrm{O},-\mathrm{O}-\mathrm{C}=\mathrm{O}$ etc. and sometimes mobile/floating functional groups like C-O-C. ${ }^{16-18,47-49}$ The gasification of oxidized carbon atoms can next occur in the form of $\mathrm{CO}$ or $\mathrm{CO}_{2}$ gas through several probable reaction pathways depending on the stationary functional group of the carbon atom and its proximity to mobile functional groups. ${ }^{14,16-18,47,50}$ Gasification leads to widening/etching of the grain edges and boundaries (Fig. 1iv), as seen previously in the SEM images (Fig. 6), with an $E_{\mathrm{A}}$ of $1.14 \pm 0.10 \mathrm{eV}$. The Raman $I_{\mathrm{D}} / I_{\mathrm{G}}$ data indicate that the density of oxidized carbon atoms increases with time within the grain interiors; however, our measurements do not directly tell us the activation energy for the gasification (Fig. 1ii) of these oxidized carbon atoms. With this said, gasification from within the grain interiors will eventually lead to the formation of small etch pits, and gasification from the edges of these etch pits will also be dictated by an $E_{\mathrm{A}}$ of $1.14 \pm 0.10 \mathrm{eV}$.

It is likely that the barrier to the oxidation of pristine grain interiors is lowered in humid air on $\mathrm{SiO}_{2}$ substrates because the roughness of the $\mathrm{SiO}_{2}$ substrate introduces local deviations in the $\mathrm{sp}^{2}$ structure (as observed in previous AFM studies) ${ }^{9,11}$ and because of charge inhomogeneity ${ }^{11,25}$ on the $\mathrm{SiO}_{2}$ substrate. This hypothesis can be further verified qualitatively from a bilayer experiment in Fig. 3c, where the topmost graphene layer is isolated from the substrate, resulting in a significantly slower degradation. The lower activation energy calculated for the interior oxidation (Fig. 3) compared to the one calculated for grain boundary etching (Fig. 7) indicates that the build-up of defects is faster (Fig. 1i) than the removal of carbon atoms via gasification (Fig. 1iv), which is why the graphene grains appear to disappear from the inside out in Fig. 6d.

\subsection{In situ temperature-dependent field-effect transport measurements}

Finally, in order to assess the effects of degradation on the electronic properties of graphene on $\mathrm{SiO}_{2}$, we use field effect transistor measurements to quantify both the doping concentration and charge carrier mobility of single layers of CVDgrown graphene in situ during degradation between $473 \mathrm{~K}$ and $673 \mathrm{~K}$ in humid air (water vapor $=15000 \mathrm{ppm}$ ). Prior to annealing, the CVD-grown graphene is p-type doped with a carrier concentration of $2.4 \times 10^{13} \mathrm{~cm}^{-2}$ and a field-effect mobility, $\mu$, of $500 \mathrm{~cm}^{2} \mathrm{~V}^{-1} \mathrm{~s}^{-1}$, at room temperature. The carrier concentration is determined by extrapolating the linear portion of the source-drain current versus gate bias transfer curve to zero-current to determine the charge neutrality gate bias, and $\mu$ is determined from the transconductance, using a standard parallel-plate capacitor model. These fit parameters are typical of graphene grown by $\mathrm{CVD}$ on $\mathrm{Cu}$ and transferred to $\mathrm{SiO}_{2} / \mathrm{Si}$ using similar conditions. ${ }^{30,51-53}$

Fig. 8 shows the evolution of the transconductance characteristics of monolayer graphene on $\mathrm{SiO}_{2}$ at $523 \mathrm{~K}$ in ambient air with time. The mobility, determined from the slope of the curve, increases rapidly to a maximum value and then starts decreasing back again with time. During the very beginning stages of annealing, the doping concentration rapidly decreases while $\mu$ increases as shown for $523 \mathrm{~K}$ in Fig. 9a and $\mathrm{b}$, respectively. These changes can be attributed to the desorption of surface contaminants, which act as charge trans- 


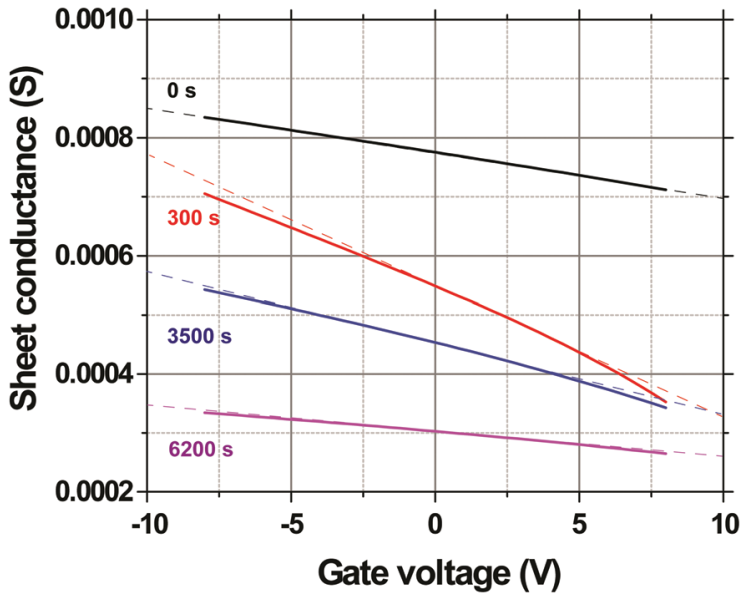

Fig. 8 Sheet conductance vs. gate voltage characteristics of monolayer graphene on $\mathrm{SiO}_{2}$ at $523 \mathrm{~K}$ vs. time. Top to bottom represents the transconductance characteristics at (i) $t=0 \mathrm{~s}$ (black), (ii) $300 \mathrm{~s}$ (red), (iii) 3500 s (blue) and (iv) $6200 \mathrm{~s}$ (pink).

fer dopants and charge scattering sites. Following this desorption, the graphene begins to degrade leading to a doping concentration that increases approximately linearly and $\mu$ that decreases with time. Our hypothesis is that $\mu$ decays mostly due to interior grain oxidation (Fig. 1i), which is based on the observation that the grains oxidize most rapidly from the interior (section 2.2) and the activation energy for this degradation (section 2.1) is lower than that of grain boundary gasification (section 2.3). Previous experiments have shown that the mobility of exfoliated monolayer graphene decays inversely with point defect density. ${ }^{28,54}$ Accordingly, we fit our $\mu$ decay data to the following form $\mu^{-1}=\mu_{0}{ }^{-1}+\lambda\left(t-t_{\mathrm{o}}\right)$, where $\mu_{0}$ is the mobility prior to degradation, $t_{\mathrm{o}}$ is the time at which the degradation begins, and $\lambda$ is the decay constant, which will be proportional to the point defect generation rate (Fig. 9b). $\lambda$ is computed by calculating the slope of the $\mu^{-1}$ vs. annealing time plot (Fig. 9b) at $\mu=500 \mathrm{~cm}^{2} \mathrm{~V} \mathrm{~s}^{-1}$, which is around the center of the range where $\mu$ exhibits an almost linear behavior. The fit decay constant $\lambda$ increases with temperature as shown in Fig. 9c, varying as $\lambda=\lambda_{673} \exp \left[\left(-E_{\mathrm{A}} / k_{\mathrm{B}}\right)(1 / T-1 / 673)\right]$ with temperature where $\lambda_{673}=(1.1 \pm 0.3) \times 10^{-5} \mathrm{~cm}^{-2} \mathrm{~V}$ and $E_{\mathrm{A}}=$ $0.66 \pm 0.08 \mathrm{eV}$ (Fig. 9c). The mobility dependent decay time can be defined as $\tau(\mu)=1 /(\lambda \mu)$. In particular, at $523 \mathrm{~K}$, the mobility dependent decay time at $\mu=500 \mathrm{~cm}^{2} \mathrm{~V} \mathrm{~s}^{-1}$ is $\tau=$ $3.6 \mathrm{k} \mathrm{s}$. It can be noted that $\mu^{-1}$ does not have an exact linear dependence on time. The non-linearity can be attributed to other mechanisms, for example the opening of grain boundaries.

\section{Implications and conclusions}

Successful integration and support of monolayer graphene on substrates, especially oxides, is an integral part of realizing electronic and optoelectronic devices with an atomic
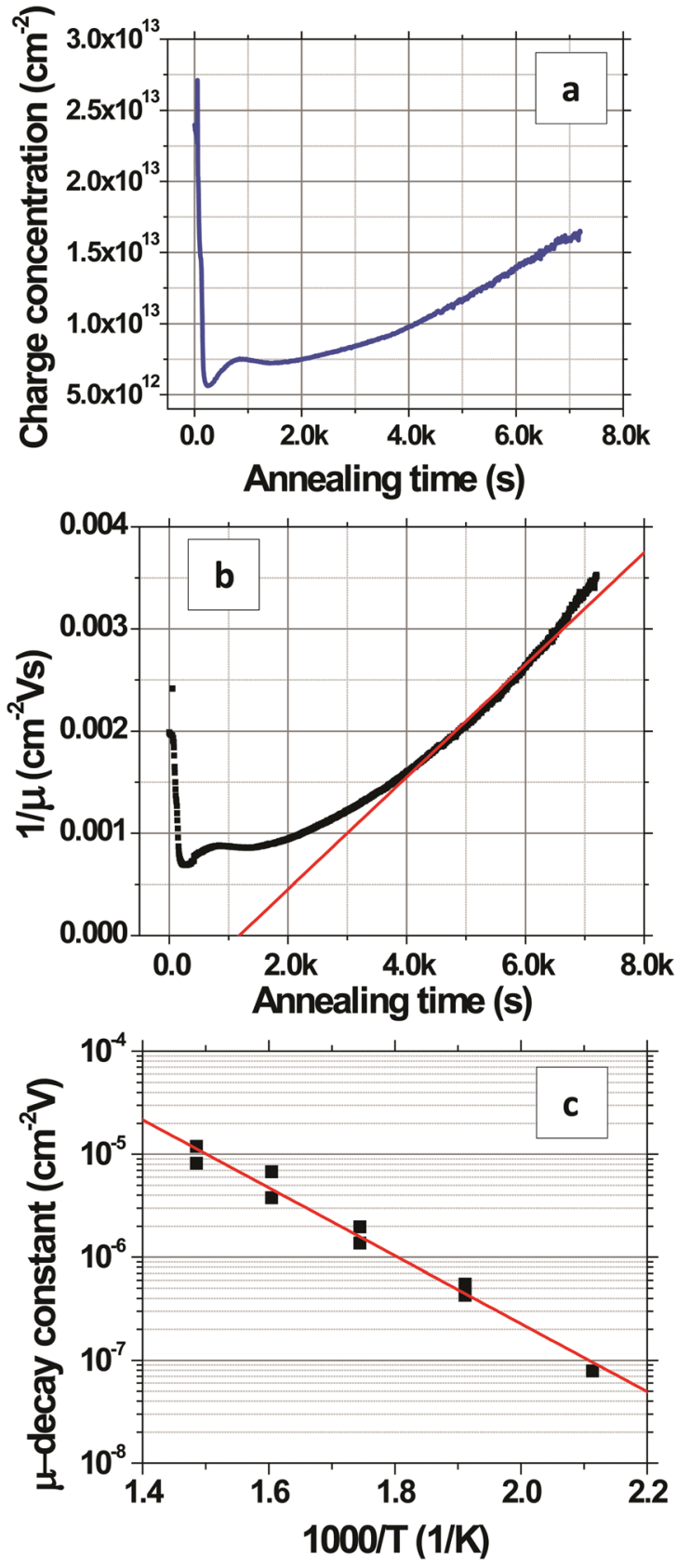

Fig. 9 Effect of degradation on transport properties of graphene: (a) and (b) represent the evolution of the charge concentration and carrier mobility, respectively, with time at $523 \mathrm{~K}$ for the CVD-graphene based FET devices on $\mathrm{SiO}_{2} / \mathrm{Si}$. Mobility vs. time plots for different temperatures are independently fit to compute the decay constants for each temperature. (c) depicts the Arrhenius dependence of the decay constant, $\lambda$, determined from the exponential decay on temperature, where $\lambda=$ $\lambda_{673} \exp \left[\left(-E_{\mathrm{A}} / k_{\mathrm{B}}\right)(1 / T-1 / 673)\right]$ and where $\lambda_{673}=(1.1 \pm 0.3) \times 10^{-5} \mathrm{~cm}^{-2} \mathrm{~V}$ and $E_{\mathrm{A}}=0.66 \pm 0.08 \mathrm{eV}$.

membrane. We find that the grain interiors of monolayer graphene oxidize at a rate $(\partial / \partial t)\left(I_{\mathrm{D}} / I_{\mathrm{G}}\right)=R_{673} \exp \left[\left(-E_{\mathrm{A}} / k_{\mathrm{B}}\right)(1 / T\right.$ - 1/673)]. In humid ambient air (15000 ppm $\left.\mathrm{H}_{2} \mathrm{O}\right)$, CVDgraphene has a $R_{673}=(3.7 \pm 0.7) \times 10^{-4} \mathrm{~s}^{-1}$ and an $E_{\mathrm{A}}=0.63 \pm$ $0.05 \mathrm{eV}$, whereas in dry air $R_{673}=(3.6 \pm 0.4) \times 10^{-5} \mathrm{~s}^{-1}$ and $E_{\mathrm{A}}=$ 
$1.85 \pm 0.17 \mathrm{eV}$. Mechanically exfoliated monolayer graphene oxidizes with similar kinetics to CVD-grown monolayer graphene. The degradation is immeasurable for exfoliated multilayers in ambient air and for CVD-monolayers in nitrogen. Etching at the grain boundaries for monolayers proceeds with a mode velocity $v=v_{673} \exp \left[\left(-E_{\mathrm{A}} / k_{\mathrm{B}}\right)\{(1 / T)-(1 / 673)\}\right]$ with $v_{673}=(1.08 \pm 0.02) \times 10^{-1} \mathrm{~nm} \mathrm{~s}^{-1}$ and $E_{\mathrm{A}}=1.14 \pm 0.10 \mathrm{eV}$. At a given temperature, the charge carrier mobility decay rate is given by $\mu^{-1}=\mu_{0}{ }^{-1}+\lambda\left(t-t_{\mathrm{o}}\right)$, and the decay constant varies as $\lambda=\lambda_{673} \exp \left[\left(-E_{\mathrm{A}} / k_{\mathrm{B}}\right)(1 / T-1 / 673)\right]$ where $\lambda_{673}=(1.1 \pm 0.3) \times$ $10^{-5} \mathrm{~cm}^{-2} \mathrm{~V}$ and $E_{\mathrm{A}}=0.66 \pm 0.08 \mathrm{eV}$.

These measurements are useful for two important reasons. Firstly, these measurements can be used to quantitatively predict the oxidative stability of monolayer graphene on $\mathrm{SiO}_{2}$ under different conditions. For example, at $298 \mathrm{~K}$ in humid (15 $000 \mathrm{ppm} \mathrm{H}_{2} \mathrm{O}$ ) ambient air, $(\partial / \partial t)\left(I_{\mathrm{D}} / I_{\mathrm{G}}\right), v$, and $\tau\left(500 \mathrm{~cm}^{2}\right.$ $\mathrm{V}^{-1} \mathrm{~s}^{-1}$ ) can be extrapolated to $4.5 \times 10^{-10} \mathrm{~s}^{-1}, 7.3 \times 10^{-5} \mathrm{~nm}$ per year and 8.4 year, respectively. Thus, the mobility of graphene exposed to humid ambient air on $\mathrm{SiO}_{2}$ is expected to be stable at room temperature for only a duration of several years. At an elevated temperature of $380 \mathrm{~K}$ the same parameters become $4.49 \times 10^{-8} \mathrm{~s}^{-1}, 1 \mathrm{~nm}$ per year, and 12.4 days, respectively. Under these conditions, mobility decay is much faster and the grain boundaries will etch leaving discontinuous graphene after roughly one year.

Secondly, these data are useful as they clearly show how graphene's stability on $\mathrm{SiO}_{2}$ can be increased. Most importantly, graphene's stability on $\mathrm{SiO}_{2}$ in ambient air can be improved by limiting its exposure to water vapor. Furthermore, degradation at grain boundaries or striations can be reduced by growing graphene with larger grains and using high quality, flatter metal catalyst substrates, respectively. Ultimately, this study is expected to serve as a foundation for overcoming the limitations posed by ambient air on graphene and help engineer graphene materials with superior properties for demanding applications.

\section{Experimental details}

\subsection{CVD-graphene growth}

Monolayers of graphene were grown on $\mathrm{Cu}$ foils (Alfa Aesar product\# 13382, lot\# B03Y027) as the growth catalyst. The foils were pre-cleaned with acetic acid (Fisher) for 15 minutes to remove contaminants and native oxides and then rinsed in DI water $(\times 3)$ before being dried with an air-gun. The cleaned $\mathrm{Cu}$ foils were then annealed for 30 minutes at $1030{ }^{\circ} \mathrm{C}$ in $95 \%$ argon $+5 \%$ hydrogen (340 sccm flow rate) to remove trace surface contaminants and also to reduce the surface roughness of the foil before initiating the growth process. The growth was conducted at $1030{ }^{\circ} \mathrm{C}$ with $95 \%$ argon $+5 \%$ methane $(0.300 \mathrm{sccm})$ and $95 \%$ argon $+5 \%$ hydrogen $(340$ sccm) for 3 hours. The manufactured graphene on $\mathrm{Cu}$ foils was stored in a $\mathrm{N}_{2}$ glovebox to prevent the oxidation of the graphene and the copper surfaces. All the graphene monolayers used for the experiments were manufactured from the same batch for consistency and the initial $I_{\mathrm{D}} / I_{\mathrm{G}}$ varied as $0.06 \pm$ 0.025 for the entire batch used for this study.

\subsection{Transfer of CVD-graphene onto $\mathrm{SiO}_{2} / \mathrm{Si}$ and mechanical exfoliation of graphene}

Graphene monolayers grown via CVD were transferred on to $\mathrm{Si}$ substrates with an $89 \mathrm{~nm}$ thick thermally-grown $\mathrm{SiO}_{2}$ layer. The transfer was completed using a commonly employed sacrificial polymer (PMMA - poly methyl methacrylate) method, similar to what has been previously reported.,27 CVD-graphene on copper was over-coated with PMMA $\left(M_{\mathrm{W}}=950 \mathrm{k}, 2 \%\right.$ in chlorobenzene) by spin-coating at $2000 \mathrm{rpm}$. The samples were placed in the copper etchant ammonium persulfate $(25 \%$ Transene company, Inc. APS- $100+75 \%$ DI water) and then ultrasonicated for 15 minutes to remove the bottom-facing graphene layer. The samples were left overnight $(\sim 10 \mathrm{~h})$ in the etchant for the copper for complete etching. Post-etching, the floating PMMA on graphene was scooped out from the APS solution and re-floated in DI water $(\times 3)$ to remove any residual copper etchant. The samples were then dispersed in 5\% HF in DI water for 60 minutes to remove trace silica particles that might have deposited from the CVD system during the growth, following which they were rinsed in DI water $(\times 3)$. From the final DI water bath, the samples were scooped onto $\mathrm{SiO}_{2} / \mathrm{Si}$ and spin-dried at $8000 \mathrm{rpm}$ for 2 minutes to remove water trapped between the graphene sheet and the substrate. To remove the PMMA layer, the samples were placed in roomtemperature acetone baths $(\times 2)$ for 20 minutes after which they were rinsed in isopropanol for 2 minutes to wash away any residual acetone. Finally, they were dried using an air-gun before being cut into several pieces for further analysis.

Mechanical exfoliation of monolayer graphene on $\mathrm{SiO}_{2}$ was done from small flakes of HOPG using the scotch-tape method that has been previously used in several other studies, and they were identified on the substrate using optical microscopy and further confirmed via Raman spectroscopy. ${ }^{55,56}$ The thickness of silicon dioxide, $89 \mathrm{~nm}$, used in the experiments creates enough contrast between the graphene and the substrate to make the graphene visible under white light in an optical microscope. In particular, the lowest contrast features indicate the presence of a single graphene layer and addition of subsequent layers increases this contrast and makes it appear darker, progressively. In the Raman spectra for an intrinsically doped monolayer graphene on $\mathrm{SiO}_{2} / \mathrm{Si}$, (i) the 2D-band to G-band ratio is always $>1$ at a $532 \mathrm{~nm}$ excitation wavelength and (ii) the $2 \mathrm{D}$ peak can be fitted to a single Lorentzian function. For a bi-layer graphene the 2D to $\mathrm{G}$ band ratio is $<1$ and the $2 \mathrm{D}$ peak can be fitted to two Lorentzian functions. ${ }^{57,58}$

\subsection{Characterization and analysis techniques}

(i) In situ Raman spectroscopy: Labram Aramis by Horiba was used for the in situ Raman studies. An enclosed heating stage (Linkam THMS 600) was integrated with an automated X-Y stage to control the temperature of the sample and atmosphere around it. A $532 \mathrm{~nm}$ laser with power $=1 \mathrm{~mW}$ and exposure 
time $=1 \mathrm{~s}$ per spot was used for all the scans to avoid substrate heating effects. Maps were collected across a fixed $100 \mu \mathrm{m} \times$ $100 \mu \mathrm{m}$ region (with a pixel size of $10 \mu \mathrm{m} \times 10 \mu \mathrm{m}$ ) at intervals of 150 seconds during the annealing period. A temperature controller was used to control the initial ramp-rate $(100 \mathrm{~K}$ $\min ^{-1}$ ) and the final hold-temperature of the stage. Gas inlets in Linkam THMS 600 were used to pump or purge the sample chamber to control the atmosphere. The heating rate used for all the measurements was $100{ }^{\circ} \mathrm{C} \mathrm{min}^{-1}$ and the measurements of relative humidity and Raman spectra were initiated after the stage had reached the set annealing temperature.

(ii) Imaging Raman spectroscopy: MicroRaman DXR from Thermofisher was used for all the spatially-resolved Raman imaging studies. A $532 \mathrm{~nm}$ laser with power $=1 \mathrm{~mW}$ and exposure time $=3 \mathrm{~s}$ per spot was used for all the scans to avoid substrate heating effects. The laser spot size was focused to $\sim 700 \mathrm{~nm}$, and a mapping pixel size of $200 \mathrm{~nm} \times 200 \mathrm{~nm}$ was used.

(iii) Scanning electron microscopy: SEM LEO 1530 was used to image the graphene on $\mathrm{SiO}_{2} / \mathrm{Si}$ samples. The electron gun energy used was $3 \mathrm{keV}$.

(iv) Image analysis: The scanning electron micrographs were analyzed via an image analysis algorithm developed using MATLAB to compute the average grain boundary width.

(v) Charge carrier mobility measurements: Graphene based field-effect transistors were made with $89 \mathrm{~nm} \mathrm{SiO}_{2}$ as the gate dielectric on a Si gate. $75 \mathrm{~nm}$ of Au was thermally evaporated through a shadow mask to form the source and drain contacts. The channel width and length were $5 \mathrm{~mm}$ and $1 \mathrm{~mm}$, respectively. The temperature was controlled using a Linkam THMS 600 during the measurements. The heating rate used for all the measurements was $100{ }^{\circ} \mathrm{C} \mathrm{min}^{-1}$ and the transconductance measurements were initiated after the stage had reached the set annealing temperature.

\section{Acknowledgements}

The majority of the experimental Raman spectroscopy and electron microscopy work was supported by the National Science Foundation (grant number CBET-1033346). The experimental Raman spectroscopy and electron microscopy were partially supported by Wisconsin Energy Institute. The in situ charge transport measurements were supported by the DOE Office of Science Early Career Research Program (grant number DE-SC0006414) through the Office of Basic Energy Sciences. The grain boundary etching analysis was supported by the University of Wisconsin-Madison, Center of Excellence for Materials Research and Innovation (National Science Foundation grant number DMR-1121288). MSA also acknowledges partial support from a 3M Non-Tenured Faculty Grant. The authors gratefully acknowledge the use of facilities and instrumentation supported by the NSF-funded University of Wisconsin Materials Research Science and Engineering Center (DMR-1121288).

\section{References}

1 H. E. Romero, N. Shen, P. Joshi, H. R. Gutierrez, S. A. Tadigadapa, J. O. Sofo and P. C. Eklund, ACS Nano, 2008, 2, 2037-2044.

2 C. A. Di, D. C. Wei, G. Yu, Y. Q. Liu, Y. L. Guo and D. B. Zhu, Adv. Mater., 2008, 20, 3289-3293.

3 Z. G. Cheng, Q. Y. Zhou, C. X. Wang, Q. A. Li, C. Wang and Y. Fang, Nano Lett., 2011, 11, 767-771.

4 F. N. Xia, T. Mueller, Y. M. Lin, A. Valdes-Garcia and P. Avouris, Nat. Nanotechnol., 2009, 4, 839-843.

5 H. Y. Nan, Z. H. Ni, J. Wang, Z. Zafar, Z. X. Shi and Y. Y. Wang, J. Raman Spectrosc., 2013, 44, 10181021.

6 S. Singha Roy and M. Arnold, Adv. Funct. Mater., 2013, 23, 3638-3644.

7 L. Liu, S. Ryu, M. R. Tomasik, E. Stolyarova, N. Jung, M. S. Hybertsen, M. L. Steigerwald, L. E. Brus and G. W. Flynn, Nano Lett., 2008, 8, 1965-1970.

8 S. S. Roy, D. J. Bindl and M. S. Arnold, J. Phys. Chem. Lett., 2012, 3, 873-878.

9 M. Ishigami, J. H. Chen, W. G. Cullen, M. S. Fuhrer and E. D. Williams, Nano Lett., 2007, 7, 1643-1648.

10 R. Sharma, J. H. Baik, C. J. Perera and M. S. Strano, Nano Lett., 2010, 10, 398-405.

11 M. Yamamoto, T. L. Einstein, M. S. Fuhrer and W. G. Cullen, ACS Nano, 2012, 6, 8335-8341.

12 P. Solis-Fernandez, J. I. Paredes, S. Villar-Rodil, L. Guardia, M. J. Fernandez-Merino, G. Dobrik, L. P. Biro, A. MartinezAlonso and J. M. D. Tascon, J. Phys. Chem. C, 2011, 115, 7956-7966.

13 J. D. Jones, C. F. Morris, G. F. Verbeck and J. M. Perez, Appl. Surf. Sci., 2013, 264, 853-863.

14 J. R. Hahn, H. Kang, S. M. Lee and Y. H. Lee, J. Phys. Chem. $B$, 1999, 103, 9944-9951.

15 J. Zhang, H. L. Zou, Q. Qing, Y. L. Yang, Q. W. Li, Z. F. Liu, X. Y. Guo and Z. L. Du, J. Phys. Chem. B, 2003, 107, 37123718.

16 K. Sendt and B. S. Haynes, Proc. Combust. Inst., 2005, 30, 2141-2149.

17 K. Sendt and B. S. Haynes, Combust. Flame, 2005, 143, 629643.

18 K. Sendt and B. S. Haynes, J. Phys. Chem. C, 2007, 111, 5465-5473.

19 M. J. Lee, J. S. Choi, J.-S. Kim, I.-S. Byun, D. H. Lee, S. Ryu, C. Lee and B. H. Park, Nano Res., 2012, 5, 710-717.

20 L. Liu, D. Xie, M. Wu, X. Yang, Z. Xu, W. Wang, X. Bai and E. Wang, Carbon, 2012, 50, 3039-3044.

21 N. Patra, B. Wang and P. Kral, Nano Lett., 2009, 9, 37663771.

22 D. Lee, G. Ahn and S. Ryu, J. Am. Chem. Soc., 2014, 136, 6634-6642.

23 L. G. Cancado, A. Jorio, E. H. Martins Ferreira, F. Stavale, C. A. Achete, R. B. Capaz, M. V. O. Moutinho, A. Lombardo, T. S. Kulmala and A. C. Ferrari, Nano Lett., 2011, 11, 31903196. 
24 A. Jorio, E. H. Martins Ferreira, M. V. O. Moutinho, F. Stavale, C. A. Achete and R. B. Capaz, Phys. Status Solidi B, 2010, 247, 2980-2982.

25 R. Decker, Y. Wang, V. W. Brar, W. Regan, H.-Z. Tsai, Q. Wu, W. Gannett, A. Zettl and M. F. Crommie, Nano Lett., 2011, 11, 2291-2295.

26 A. Eckmann, A. Felten, I. Verzhbitskiy, R. Davey and C. Casiraghi, Phys. Rev. B: Condens. Matter, 2013, 88, 035426.

27 X. Li, Y. Zhu, W. Cai, M. Borysiak, B. Han, D. Chen, R. D. Piner, L. Colombo and R. S. Ruoff, Nano Lett., 2009, 9, 4359-4363.

28 J.-H. Chen, W. G. Cullen, C. Jang, M. S. Fuhrer and E. D. Williams, Phys. Rev. Lett., 2009, 102, 215504.

29 K. I. Bolotin, K. J. Sikes, Z. Jiang, M. Klima, G. Fudenberg, J. Hone, P. Kim and H. L. Stormer, Solid State Commun., 2008, 146, 351-355.

30 A. Venugopal, J. Chan, X. Li, C. W. Magnuson, W. P. Kirk, L. Colombo, R. S. Ruoff and E. M. Vogel, J. Appl. Phys., 2011, 109, 104511.

31 S. Niyogi, M. A. Hamon, H. Hu, B. Zhao, P. Bhowmik, R. Sen, M. E. Itkis and R. C. Haddon, Acc. Chem. Res., 2002, 35, 1105-1113.

32 X. Chu and L. D. Schmidt, Surf. Sci., 1992, 268, 325-332.

33 K. Kim, W. Regan, B. Geng, B. Aleman, B. M. Kessler, F. Wang, M. F. Crommie and A. Zettl, Phys. Status Solidi $R R L, 2010,4,302-304$.

34 W. A. de Heer, C. Berger, X. S. Wu, P. N. First, E. H. Conrad, X. B. Li, T. B. Li, M. Sprinkle, J. Hass, M. L. Sadowski, M. Potemski and G. Martinez, Solid State Commun., 2007, 143, 92-100.

35 C. Berger, Z. M. Song, T. B. Li, X. B. Li, A. Y. Ogbazghi, R. Feng, Z. T. Dai, A. N. Marchenkov, E. H. Conrad, P. N. First and W. A. de Heer, J. Phys. Chem. B, 2004, 108, 19912-19916.

36 S. Shivaraman, M. V. S. Chandrashekhar, J. J. Boeckl and M. G. Spencer, J. Electron. Mater., 2009, 38, 725-730.

37 L. Blackberg, A. Ringbom, H. Sjostrand and M. Klintenberg, Phys. Rev. B: Condens. Matter, 2010, 82, 4.

38 J. Chen, T. Shi, T. Cai, T. Xu, L. Sun, X. Wu and D. Yu, Appl. Phys. Lett., 2013, 102, 103107.

39 Y. Lin, K. A. Watson, J.-W. Kim, D. W. Baggett, D. C. Working and J. W. Connell, Nanoscale, 2013, 5, 78147824.

40 J. G. Radich and P. V. Kamat, ACS Nano, 2013, 7, 55465557.
41 B. Wang, Y. S. Puzyrev and S. T. Pantelides, Polyhedron, 2013, 64, 158-162.

42 W. J. Zhu, T. Low, V. Perebeinos, A. A. Bol, Y. Zhu, H. G. Yan, J. Tersoff and P. Avouris, Nano Lett., 2012, 12, 3431-3436.

43 S. P. Surwade, Z. T. Li and H. T. Liu, J. Phys. Chem. C, 2012, 116, 20600-20606.

44 E. Loren Fuller and J. M. Okoh, J. Nucl. Mater., 1997, 240, 241-250.

45 F. Stevens, L. A. Kolodny and T. P. Beebe, J. Phys. Chem. B, 1998, 102, 10799-10804.

46 J. R. Hahn, Carbon, 2005, 43, 1506-1511.

47 D. Yafei, N. Shuang, L. Zhenyu and Y. Jinlong, J. Phys.: Condens. Matter, 2013, 25, 405301-405306.

48 L. R. Radovic, A. B. Silva-Tapia and F. Vallejos-Burgos, Carbon, 2011, 49, 4218-4225.

49 L. R. Radovic, A. Suarez, F. Vallejos-Burgos and J. O. Sofo, Carbon, 2011, 49, 4226-4238.

50 X. Qi, X. Guo and C. Zheng, Appl. Surf. Sci., 2012, 259, 195200.

51 J. Heo, H. J. Chung, S.-H. Lee, H. Yang, D. H. Seo, J. K. Shin, U. I. Chung, S. Seo, E. H. Hwang and S. Das Sarma, Phys. Rev. B: Condens. Matter, 2011, 84, 035421.

52 N. S. Safron, M. Kim, P. Gopalan and M. S. Arnold, Adv. Mater., 2012, 24.

53 M. Kim, N. S. Safron, E. Han, M. S. Arnold and P. Gopalan, ACS Nano, 2012, 6, 9846-9854.

54 Z. H. Ni, L. A. Ponomarenko, R. R. Nair, R. Yang, S. Anissimova, I. V. Grigorieva, F. Schedin, P. Blake, Z. X. Shen, E. H. Hill, K. S. Novoselov and A. K. Geim, Nano Lett., 2010, 10, 3868-3872.

55 L. Ciric, A. Sienkiewicz, B. Nafradi, M. Mionic, A. Magrez and L. Forro, Phys. Status Solidi B, 2009, 246, 25582561.

56 J. S. Bunch, A. M. van der Zande, S. S. Verbridge, I. W. Frank, D. M. Tanenbaum, J. M. Parpia, H. G. Craighead and P. L. McEuen, Science, 2007, 315, 490493.

57 A. C. Ferrari, J. C. Meyer, V. Scardaci, C. Casiraghi, M. Lazzeri, F. Mauri, S. Piscanec, D. Jiang, K. S. Novoselov, S. Roth and A. K. Geim, Phys. Rev. Lett., 2006, 97, 187401.

58 L. M. Malard, M. A. Pimenta, G. Dresselhaus and M. S. Dresselhaus, Phys. Rep.: Rev. Sec. Phys. Lett., 2009, 473, 51-87. 